\title{
The Influence of Physical Education Lesson Context and Teacher Behaviour on Student Physical Activity in Mexico \\ La influencia del contexto de la clase de educación física y de los comportamientos docentes en la actividad física de los alumnos en México
}

\author{
Hoda Gharib*, Karla I. Galavíz ${ }^{* *}$, Rebecca E. Lee ${ }^{* * *}$, Margarita Safdie $^{* * * *}$,Lizbeth Tolentino ${ }^{* * * *}$, Símon Barquera ${ }^{* * * *}$, \\ Lucie Lévesque*
}

${ }^{*}$ Queen’s University, Kingston (Canada), ${ }^{* *}$ Emory University, Atlanta (United States of America), ${ }^{* * *}$ Arizona State University; Phoenix (United States of America), ${ }^{* * * *}$ Instituto Estatal de Cancerología de los Servicios de Salud del Estado de Colima (México), ${ }^{* * * * *}$ Instituto Nacional de Salud Pública de México, Cuernavaca (México)

\begin{abstract}
Objective: To explore the influence of physical education (PE) lesson context and teacher behaviour on moderate-to-vigorous physical activity (MVPA) in Mexican children during PE class. Methods: Trained observers rated the physical activity intensity (lying down, sitting, standing, walking, vigorous movement) of 232 students from grades 3 to 5, PE lesson context (management, general knowledge, fitness knowledge, fitness, skill practice, game play, free play), and teacher behaviour (promoting fitness, demonstrating, instructing, observing, managing, other task) during PE class in 20 public elementary schools in Mexico City using the System for Observing Fitness Instruction Time (SOFIT). Regressions with backward elimination were conducted. Results: Class duration was on average 33.6 minutes $(S D=7.9)$. Boys $(M=14.8 \mathrm{~min}, S D=6.8)$ spent more time in MVPA than girls ( $M=12.6 \mathrm{~min}, S D=6.1 ; p<.01)$. For boys, a model including game play $(\beta=1.04, p<.001)$, skill practice $(\beta=.54, p<.01)$, and fitness $(\beta=.53$, $p<.05$ ) explained $45 \%$ of the variance in MVPA $(p<.05)$. For girls, a model including fitness $(\beta=.49, p<.05)$, fitness knowledge $(\beta=.19, p<.05)$, and other task $(\beta=.35, p<.05)$ explained 38\% of the variance in MVPA $(p<.05)$. Conclusion: Strategies and policies aimed at improving child physical activity levels during PE class should endorse the effective instruction and execution of fitness, game play, skill practice and PE lesson contexts. Keywords. SOFIT; policies; MVPA; youth.
\end{abstract}

Resumen. Objetivo: Explorar la influencia del contexto de las clases de educación física (EF) y el comportamiento del maestro en la actividad física moderada-vigorosa (AFMV) en niños mexicanos. Métodos: Usando el método Sistema de Observación del Tiempo de Instrucción de la condición Física (SOFIT). Observadores entrenados midieron la intensidad de la actividad física (acostado, sentado, de pie, caminando, movimiento vigoroso) de 232 estudiantes de 3ro a 5to grado, el contexto de la clase, (gestión, conocimiento general, conocimiento de la condición física, condición física, práctica de habilidades, juego, juego libre), y el comportamiento del maestro (promoción de la condición física, demostración, instrucción, observación, gestión, otra tarea) durante la clase de EF en 20 escuelas públicas de educación primaria de la ciudad de México mediante el SOFIT. Se llevaron a cabo regresiones múltiples. Resultados: La duración promedio de las clases observadas fue de 33.6 minutos (DE = 7.9). Los niños $(\mathrm{M}=14.8$ min, DE = 6,8) pasaron más tiempo en AFMV que las niñas ( $\mathrm{M}=12.6 \mathrm{~min}, \mathrm{DE}=6.1$; $\mathrm{p}<.01$ ). En niños, el tiempo de clase dedicado al juego (â= 1.04, $\mathrm{p}<.001$ ), la práctica de habilidades ( $\mathrm{a}=.54, \mathrm{p}<.01$ ) y la condición física $(\hat{a}=.53, \mathrm{p}<.05)$ explico el $45 \%$ de la varianza en AFMV ( $<.05)$. En niñas, el tiempo de clase dedicado a la condición física (â= .49, p <.05), al conocimiento sobre la condición física (â= .19, p <.05), y otras tarea (â= .35, p <.05) explico el 38\% de la varianza en AFMV ( $\mathrm{p}<.05$ ). Conclusión: Las estrategias y políticas encaminadas a la mejora de los niveles de actividad física de los niños durante la clase de EF deben suscribir la enseñanza efectiva y la promoción de la condición física, el juego, y el desarrollo de las habilidades prácticas.

Palabras Clave. SOFIT; políticas; AFMV; la juventud.

\section{Introduction}

Approximately $40 \%$ of Mexican children do not meet the international World Health Organization (WHO) physical activity guidelines (Shamah, Villalpando, \& Rivera, 2006), which call for children to participate in at least 60 minutes of moderate-to-vigorous physical activity (MVPA) per day (WHO, 2010). Schools are considered to be the most cost-effective public health resource in which to address inactivity (Abonce, Lopez, Gonzalez, Ocariz, \& Benitez, 2010; McKenzie \& Lounsbery, 2013; Sallis \& McKenzie, 1991; Sallis et al., 2012) and physical education (PE) class is recognized as an important setting for promoting physical activity engagement in children because it provides the opportunity to reach a large number of children at one time (Dobbins, De Corby, Robeson, Husson, \& Tirilis, 2009; Marshall \& Hardman, 2000; McKenzie et al., 1995). PE class typically offers a safe, structured setting in which children can engage in physical activity and learn fundamental physical skills and general health practices that can carry into adulthood. Evidence suggests that children who acquire a solid foundation of fundamental movement skills (e.g. kicking a ball) are more likely to be active throughout their life in comparison to children who have not built these skills (Bailey, 2006). PE class has, thus, become a preferred setting for promoting physical activity and a common policy target in high income countries, such as Canada (Cameron et al., 2007) and the United States of America (McKenzie et al., 2010). Little is known, however, about PE class in low-to-middle income countries such as Mexico, limiting the evidence from which policy makers can draw to create evidence-based policies to enhance physical activity

Fecha recepción: 30-09-14- Fecha envío revisores: 30-09-14- Fecha de aceptación: 15-11-14 Lucie Lévesque

levesqul@queensu.ca during school hours. It is thus imperative to study PE class in Mexican schools to better understand how PE class is implemented, how much physical activity children are getting, and which contextual factors are related to children's physical activity.

Studies examining PE classes in the United States of America indicate that grade 3 and middle school (grades 6-8) PE classes are held for less than 35 minutes on average and that students engage in MVPA for less than $50 \%$ of class time (McKenzie, Marshall, Sallis, \& Conway, 2000; Nader, 2003; Simons-Morton, Taylor, Snider, \& Huang, 1993). Student activity levels have been shown to vary by PE lesson context and teacher behaviour (McKenzie et al., 1995; McKenzie et al., 2000). Evidence shows that boys are most active during fitness PE lesson contexts (e.g. calisthenics) and free play PE lesson contexts (e.g. unstructured, recess like activity), while girls are most active during fitness PE lesson contexts compared to other PE lesson contexts. These findings are similar to those from a study by Jennings-Aburto and colleagues (2009) who reported that grade 4 and 5 PE classes in 12 schools in Mexico City were held on average once a week, for a duration of 39.7 minutes, indicating that some Mexico City schools are not meeting the government mandated regulation of twice weekly, 50 minute PE classes (Administración Federal de Servicios Educativos en el Distrito Federal, 2006). The authors also reported that students spent 12 minutes, or $29.2 \%$ of class time, in MVPA, with boys more active than girls. Consistent with studies conducted in the United States of America, Jennings-Aburto and colleagues (2009) found a significant positive association between boys' MVPA and free play PE lesson contexts. However, contrary to findings by McKenzie and colleagues (1995; 2000), Jennings-Aburto and colleagues (2009) found that girls'MVPA was negatively associated with fitness PE lesson context.

The relationship among type of PE lesson context and teacher behaviour and MVPA in boys and girls remains unclear. Jennings- 
Aburto and coauthors' study (2009) is the first study to examine the association between PE lesson context and physical activity in Mexican children. However, this study is limited in its analysis and discussion of the association between PE lesson context and MVPA, and it does not explore the relationship between teacher behaviour and MVPA. Understanding how PE lesson context and teacher behaviour are related to student physical activity levels during PE class can inform policies, strategies, and curricula to enhance MVPAlevels during PE class (Dyson, 2014; Sallis et al., 2012). The purpose of this study was to determine which elements of PE lesson context and teacher behaviour contribute most to MVPA in Mexican school-aged children. We hypothesized that boys would display higher levels of MVPA during PE class in comparison to girls; that active PE lesson contexts (i.e. fitness, skill practice, and game play) and teacher's promoting fitness behaviour would positively influence student MVPA; and that the influence of PE lesson contexts and teacher behaviours would differ between boys and girls.

\section{Methods}

\section{Study Setting/Design}

This cross-sectional study was conducted as part of a larger project assessing the implementation and impact of the Program for Action within the School Context (Programa de Acción en el Contexto Escolar; PACE) on the physical activity and eating behaviours of Mexican children. This study received clearance from the General Research Ethics Board at Queen's University and the Instituto Nacional de Salud Pública (INSP) Ethics Commission. PACE was launched in 2010 with the aim to improve the food and physical activity environment in Mexican elementary schools as a way to address the growing obesity issue in the country (Diario Oficial de la Federación, 2014). While the majority of recommended actions within the policy pertain to nutrition, some of the recommended actions seek to improve the physical activity opportunities available to children at school. Schools are mandated to provide physical activation (low impact movements with music, led by a teacher) at least four times a week for 20 minutes, PE class at least twice a week, organized games at recess, and enhanced promotion of physical activity (e.g. teacher encouragement and reinforcement of physical activity).

In Mexico, public schools are regulated by the federal-level Secretary of Public Education, which determines the curricula. Basic public education is split into several stages: preschool (pre-escolar; children aged three to five), primary school education (primaria; grades 1 to 6 ), junior high school (secundaria; grades 7 to 9), and high school (preparatoria; grades 10 to 12). Only primary and junior high school education are mandatory for all Mexicans. Most primary schools operate in shifts, with the morning shift attending school from approximately 8:00am to $12: 30 \mathrm{pm}$ and the second shift attending from 1:00pm to $5: 30 \mathrm{pm}$.

\section{Sample}

As a collaborator and partner on the Advisory Board for the larger policy-evaluation project, the Secretary of Public Education provided the research team with access to schools serving families of low-tomiddle income and located in the south of Mexico City. For the sake of convenience, the selection of schools was constrained to those located in two «delegaciones» (administrative zones that comprise Mexico City): Coyoacán and Tlalpan. Of 274 primary schools, 72 schools met the following inclusion criteria: 1) be a part-time school with a morning shift (to control for time spent at school), 2) have at least 450 students in the school, 3) have two or more classes per grade, and 4) have one indoor and one outdoor area for physical activity (to control for school infrastructure), and 20 schools were randomly selected and agreed to participate. From each school, three classes were randomly selected, one from each of grades 3, 4, and 5. A total of 30 students from each of the selected classes were given two consent forms, one for themselves and one for their parents. On average, 18 students from each class brought back both consent forms and were included in a class-specific list. From each list, four students (two girls and two boys) were randomly selected for observation during PE class. Consenting teachers leading the PE class on the day of observation were also observed.

\begin{tabular}{|c|c|}
\hline Indicator & Definition \\
\hline Activity & Student: \\
\hline Lying** & Is lying down \\
\hline Sitt ing** & Is sitting \\
\hline Standing** & Is standing \\
\hline Walking & Is wal king \\
\hline Vigorous movement & Is active such that they expend more energy than they would if they were walking \\
\hline Les son Context & Time spent: \\
\hline Management & In activ ities unrelated to instructional activity (e.g., taking at tendance) \\
\hline General knowledge & Knowledge unrel ated to physical activity is being relayed \\
\hline Fitness knowledge & Knowledge related to physi cal activity is being rel ayed \\
\hline Fitness & In activ ities ai med at improving students' fitness \\
\hline Skill practice & $\begin{array}{l}\text { Practicing skills with the aim of skill development } \\
\text { Pand }\end{array}$ \\
\hline Game play & Playing a competitive game or application of skills into a game \\
\hline Free play & Free play in which physical education instruction is not intended \\
\hline $\begin{array}{l}\text { Ranked Teacher } \\
\text { Behaviours }\end{array}$ & Teacher is: \\
\hline Promoting fitness & Promp ting and/or encouraging fitness and participation of a student during PE class \\
\hline Demonstrating & Demonstrat ing or model ing fitness eng agement \\
\hline Instructing & Lecturing, describing, or providing feed back to students \\
\hline Managing & Managing activities not related to physical education \\
\hline Observing & Observing the class \\
\hline Other task & Attending to activities not related to responsibilities to the class at hand \\
\hline $\begin{array}{l}\text { *(McKenzie et al., } 19 \\
\text { **These indicators ar }\end{array}$ & \\
\hline
\end{tabular}

\section{Measures and Procedures}

The System for Observing Fitness Instruction Time (SOFIT; McKenzie, Sallis, \& Nader, 1991), a direct observation PE assessment tool, was used to assess three indicators: 1) intensity of student activity (lying down, sitting, standing, walking, vigorous movement) as performed by select students during PE class; 2) PE lesson context (management, general knowledge, fitness knowledge, fitness, skill practice, game play, free play); and, 3) teacher behaviour (promoting fitness, demonstrating, instructing, observing, managing, other task). Table 1 presents detailed definitions for each. Student activity intensity categories have been calibrated using heart rate monitors (McKenzie et al., 1991; Rowe, Schuldheisz, \& Van der Mars, 1997) and SOFIT has been shown to have good criterion validity with tri-trac accelerometers $(r=.60)$ in a grade 3 to 5 population of mostly Hispanic students (Pope, Coleman, Gonzalez, Barron, \& Heath, 2002). Finally, SOFIT has been shown to have strong inter-observer reliability with agreement rates ranging from 88-92\% (McKenzie et al., 1991)

Trained observers visited each of the 20 schools during prescheduled times and collected data from each class once between October 2011 and March of 2012. As per the SOFIT protocol, the observers began observing the student, the PE lesson context, and teacher behaviour when the teacher and $51 \%$ of the class arrived at the place of instruction. Prior to the commencement of PE class, an observer sat in an area where he or she could hear and observe the teacher, the students, and the context of the lesson without interfering with the class. If a student and/ or teacher were no longer in view, observers could move around to get a better view. They did not talk to the students nor give any feedback to the teachers. The teachers were not told which students were being observed to avoid biasing their behaviour and, in turn, the behaviour of the student. The typical number of weekly PE classes was obtained and the start and end time of each observed PE class was recorded to calculate total class duration.

In each of the 20 schools, four children from three PE classes (grades 3, 4, and 5) were observed. Following the SOFIT protocol (McKenzie et al., 1991), observers collected data in 20-second intervals, with the first 10 seconds reserved for observing the activity level of a randomly pre-selected consenting student, the PE lesson context, and the behaviour of the teacher, and the subsequent 10 seconds for recording what they observed (i.e., circling the letter corresponding to the activity level, PE lesson context, and teacher behaviour). An audio-recorded prompt marked the end of the 10-second observation interval and observers recorded the activity level of the child and the PE lesson context that occurred at the time of the prompt. For example, if a student was running (vigorous movement) and the class was playing soccer (game play context) at the time of the prompt, the trained observer would circle the codes pertaining to «vigorous movement» 
and «game play». As per the SOFIT protocol (McKenzie et al., 1991), four randomly pre-selected students were each observed for four minutes on a rotational basis throughout the entire class ( $M=33.6$ minutes class duration; range 12-51 minutes), yielding $M=100.8$ observations; range 36-153 observations.

\section{Main outcome}

Intensity of student activity was used to construct the main outcome variable: Number of PE minutes spent in MVPA. First, the total number of recordings for «walking» and «vigorous movement» were tallied for each of the four students observed in a class. Walking at a pace of 3 to $4.5 \mathrm{mph}$ is defined by the American College of Sports Medicine (Kaminsky, 2006) and the Canadian Society for Exercise Physiology (website) as moderate level physical activity. Given that we were only interested in MVPA, «lying down», «sitting», and «standing» behaviours were not included in the MVPA score. For example, if a student was observed walking for two of 12 observation intervals and running for six of the same 12 observation intervals, «walking» would get a score of 2 and «vigorous movement» a score of 6 for a student MVPA score of 8 $(2+6=8)$. To calculate number of PE minutes spent in MVPA, the student MVPAscore was divided by the number of observation intervals (8/12=0.667) and multiplied by minutes of class duration (e.g., $0.667 \mathrm{x}$ 16 minutes $=10.7$ minutes).

\section{Predictors}

Seven PE lesson context scores were calculated, representing the relative proportion of $\mathrm{PE}$ class time spent in each category of $\mathrm{PE}$ lesson context. First, the total number of observations for each of the seven PE lesson contexts recorded during the prompted observation intervals were tallied, yielding a PE lesson context score for each type of PE lesson context. To calculate Number of PE minutes spent in each PE lesson context (management, general knowledge, fitness knowledge, fitness, skill practice, game play, free play), each of the seven PE lesson context scores was divided by the total number of observation intervals for the entire class, then multiplied by minutes of class duration.

Six types of teacher behaviour were observed throughout each 10second observation interval and were coded according to a hierarchical system in which behaviours ranked higher in the system were given precedence over lower ranked behaviours (see Table 1 for rankings). For example, ahigher ranked behaviour (promoting fitness) would berecorded if it occurred at any point in a 10-second observation interval, regardless of its duration and any other behaviours observed within the same observation interval. Behaviours ranked lower on the hierarchy would only be recorded in the absence of higher ranked behaviours. For example, «managing» would only be recorded if «promoting fitness», «demonstrating», and «instructing» did not occur during the same observation interval. The number of times each category of teacher behaviour occurred during all of the observation intervals (i.e., during the entire class) was tallied, yielding a score for each type of teacher behaviour (promoting fitness, demonstrating, instructing, observing, managing, other task). To calculate Number of PE minutes the teacher spent engaged in each behaviour, each of the six teacher behaviour scores was divided by the total number of observation intervals for the entire class, then multiplied by minutes of class duration.

\section{Analysis}

Descriptive statistics were used to describe the characteristics of the students in each school, the number of classes, teachers, and students observed, the average class duration, and the average MVPA minutes and percentage of time spent in MVPA for girls and boys separately. Independent t-tests were then conducted to determine if there was a significant difference in the average number of PE minutes spent in MVPA between boys and girls.

Multiple linear regressions using the backward elimination method were conducted to explore the influence of sex and minutes spent in each PE lesson context and teacher behaviour on students' MVPA. The interaction between sex and the SOFIT variables was also tested and we found significant interactions for fitness knowledge $(\beta=-.63, p<.01)$ and game play $(\beta=.13, p<.05)$. Based on this, we conducted separate regression analyses for boys and girls. The «managing» teacher behaviour variable was excluded to avoid multicollinearity, as this variable was highly correlated with «management» from PE lesson context ( $r=.84)$. The «fitness knowledge» PE lesson context variable was also excluded in the final regression model for boys because boys were never exposed to the fitness knowledge PE lesson context while they were being observed. Analyses were conducted in the Statistical Package for Social Sciences version 20 for Windows. Statistical significance was set at alpha 05 .

\section{Results}

A total of 232 students (boys=116), 58 mixed-sex classes, and 58 teachers were observed. Two PE classes were cancelled by the schools and consequently were not assessed. Of the classes observed, 19 were grade 3 classes, 20 were grade 4 classes, and 19 were grade 5 classes. Of the teachers observed, 17 were PE specialists, 37 were generalists, and four were of unknown specialty. The 20 primary schools had an average of 336 grade 3 to grade 5 students.

Table 2 shows that on average, PE classes lasted $33.6(S D=7.9)$ minutes ranging from 12 minutes to 51 minutes. Boys spent significantly more PE time in MVPA $(M=14.8 \mathrm{~min}, S D=6.8)$ than girls $(M=12.6$ min, $S D=6.1, p<.001)$. The most prevalent $P E$ lesson contexts were game play ( $M=10.4 \mathrm{~min}, S D=10.1)$ and fitness $(M=8.1 \mathrm{~min}, S D=7.6)$, while the most common behaviour exhibited by the teacher was fitness promotion ( $M=15.9 \mathrm{~min}, S D=8.7$; Table 2).

Table 2

Average class duration and means and standard deviations of minutes and percentage of class time spent in Average class duration and means and standard deviations
MVPA, each PE lesson context, and each teacher behaviour

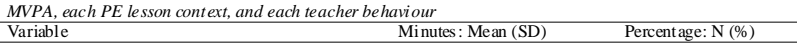
\begin{tabular}{lcc} 
Variable & Minutes: Mean (SD) & Percentage: N (\%) \\
\hline Cass Duration & $33.6(7.86)$ & - \\
\hline
\end{tabular} \begin{tabular}{lll}
\hline MVPA & $33.6(7.86)$ & \\
\hline Boys & $14.8(6.8)^{*}$ & $44.0(17.7)$
\end{tabular} \begin{tabular}{lll} 
MVPA & $14.8(6.8)^{*}$ & $44.0(17.7)$ \\
Girls & $12.6(6.1)^{*}$ & $38.1(16.7)$ \\
\hline
\end{tabular} \begin{tabular}{lll}
\hline Lesson Context & & \\
\hline Management & $4.9(5.1)$ & $159(16.3)$
\end{tabular} $\begin{array}{lrr}\text { General knowledge } & 3.7(4.5) & 10.7(12.9) \\ \text { Fines knowledge } & 0.1(0.67) & 0.1(1.7)\end{array}$ Fitness knowledge Fitness

Skill practic

Game play
Free play Ranked Teacher Behaviours (a) $\begin{array}{llc}\text { Demonstrating } & 0.3(0.9) & 0.8(2.8) \\ \text { Instucting } & 4.7(4.6) & 135(12.9) \\ & & 6.9(5.7)\end{array}$ Managing Observing Other task Signi ficant differences found between girls' and bo ys' MVPA levels: * ${ }^{*}<.001$

Table 3 displays the standardized coefficients for each of the predictor variables, stratified by sex. The model for boys, which included six PE lesson context variables (management, general knowledge, fitness, skill practice, game play, free play) and five teacher behaviour variables (promoting fitness, demonstrating, instructing, observing, other task) explained $45 \%$ of the variance in boys' Number of PE minutes spent in MVPA $\left(r^{2}=.50, p<.001\right)$. However, only three PE lesson context variables were positively associated with Number of PE minutes spent in MVPA: game play $(\beta=1.04, p<.001)$, skill practice $(\beta=.54, p<.01)$, and fitness $(\beta=.53, p<.05)$. None of the teacher behaviour variables showed significant associations with Number of PE minutes spent in MVPA by boys $(p>.05)$.

Table 3

Standardized regression coefficients showing the influ ence of $P E$ lesson context and teacher behaviour variables on Number of PE Minutes spent in MVPA

\begin{tabular}{|c|c|c|}
\hline & Boys $^{a}$ & Girl $^{\mathrm{b}}$ \\
\hline Variable & $\frac{1}{\beta}$ & $\beta$ \\
\hline \multicolumn{3}{|l|}{ Less on Context } \\
\hline M anagement & .15 & .09 \\
\hline General knowledge & .17 & .05 \\
\hline F itness knowledge & -. & $.19 * * *$ \\
\hline Fitness & $.53^{* * *}$ & $.49 * * *$ \\
\hline Skill practice & $.54^{* *}$ & .24 \\
\hline Game play & $1.04^{*}$ & .29 \\
\hline $\begin{array}{l}\text { Free play } \\
\text { Fon }\end{array}$ & .09 & . -17 \\
\hline \multicolumn{3}{|l|}{ Teacher Behaviour } \\
\hline Promoting fitness & -.21 & .19 \\
\hline Demonstrating & .02 & -.08 \\
\hline Instructing & -.16 & .01 \\
\hline Observing & .05 & .14 \\
\hline Other task & .11 & $.35 * * *$ \\
\hline
\end{tabular}

aAdjusted $R^{2}=.45 ;$ bAdjusted $R^{2}=.38$
${ }^{*} p<.001 ; * * p<.01 ; * * * p<.05$ 
The model for girls, which included seven PE lesson context variables (management, general knowledge, fitness knowledge, fitness, skill practice, game play, free play) and five teacher behaviour variables (promoting fitness, demonstrating, instructing, observing, other task) explained $38 \%$ of the variance in Number of PE minutes spent in MVPA for girls $\left(r^{2}=.45, p<.001\right)$. Fitness $(\beta=.49, p<.05)$ and fitness knowledge $(\beta=.19, p<.05)$ were the sole PE lesson context variables that significantly influenced Number of PE minutes spent in MVPA positively. Other task of the teacher behaviour variables was the only teacher behaviour variable associated with Number of PE minutes spent in MVPA by girls $(\beta=.35, p>.05)$.

\section{Discussion}

The main objective of this study was to explore the influence of PE lesson context and teacher behaviour during PE class on children's MVPA. Our findings indicate that boys engaged in significantly more MVPAthan girls during PE class. Furthermore, game play, skill practice, and fitness contexts positively influenced MVPA in boys, while fitness and fitness knowledge contexts and other tasks of teacher behaviour positively impacted MVPA in girls.

The difference in activity level between boys and girls is consistent with many studies in similar and different populations and contexts (Jennings-Aburto et al., 2009; McKenzie et al., 1995; McKenzie et al., 2000; Te Velde et al., 2007). However, both boys and girls spent less than half of PE class time in MVPA, falling well below the Healthy People 2010 objectives in the United States, which recommend that students spend at least 50\% of PE class time in MVPA (McKenzie et al., 2000). Our findings are similar to previous research in the United States of America (Skala, Springer, Sharma, Hoelscher, \& Kelder, 2012) and in Mexico (Jennings-Aburto et al., 2009), which have found that students are typically spending between a quarter to a third of PE class time engaged in MVPA.

Lack of opportunity to be active in PE class may be playing a role in the low MVPA levels found in this sample of children. Previous studies conducted in Mexico City and American elementary schools report that students often lose time to be active because they have to watch others while they wait for their turn to use equipment (Jauregui et al., 2011; Jennings-Aburto et al., 2009; Simons-Morton et al., 1993). Activity levels may also suffer if transition time between activities is conducted inefficiently. For example, opportunity to engage in MVPA may be lost while new teams are assigned or instructions are repeated by the teacher (Simons-Morton et al., 1993). Thus, teachers should be trained to efficiently manage the class such that transition time between activities is minimized and time spent being active is maximized. Similarly, the speciality of the teacher instructing the class may influence activity levels during PE class. Approximately two-thirds of the PE classes observed were led by generalists while about a third were led by specialist teachers. There is some evidence to suggest that generalists teach shorter classes than specialists and that students in a class taught by a generalist may spend less time being active, even after class duration is taken into account (McKenzie et al., 1991; Sallis et al., 1997). Thus, the large quantity of generalist teachers instructing PE classes in our sample may be contributing to the low levels of MVPA during PE class.

Our results confirm findings from previous studies demonstrating the positive influence of PE lesson context on children's MVPA. The impact of game play, fitness, and skill practice PE lesson contexts on MVPA is not surprising. Inherently, these contexts are «active» contexts, in which physical activity is occurring. In contrast, other contexts, such as management, are by nature, «sedentary» or «inactive» contexts as students are often sitting or standing while activities of that context (e.g. taking attendance) occur. For example, McKenzie and colleagues (1995) found that the energy expended by students' during one minute of management was approximately two-thirds of that expended during one minute of fitness. Therefore, our study confirms previous findings that the provision of active contexts is crucial for ensuring that students engage in MVPA, particularly for boys.
While the fitness context appears to impact both boys and girls, game play and skill practice only proved influential for boys' MVPA engagement. This finding is consistent with McKenzie and colleagues' (2000) study in middle schools that found boys to be more active than girls during skill practice, game play, and free play contexts. Differences in preferences for the various contexts and different types of activity offerings might help explain this finding. Previous studies have found that, when given the choice, girls often pick moderate and vigorous activities that are individual and expressive, such as gymnastics or dance (i.e. fitness class context), while boys often pick very vigorous, competitive, team-based physical activity such as soccer (i.e. game play context; Cherney \& London, 2006; van Mechelen, Twisk, Post, Snel, \& Kemper, 2000). Girls' and boys' preferences for an activity or types of activities might influence their motivation to participate in that activity, and this, in turn, might translate into how active they are in that activity. PE class activities might be more tailored towards the preferences of boys, thus, contributing to boys' higher activity level in comparison to girls'. For example, about a third of class time was spent in game play context, which was found to be the PE lesson context most strongly associated with boys' MVPA. Balancing contexts and activities to suit various preferences of physical activities might help to enhance MVPA participation and create a more equitable PE class environment.

The role of the teacher in shaping the context of the class must be highlighted. Although there is a standard curriculum that must be followed, it is largely the teacher instructing the class who determines the PE lesson context and how the class operates on a day-to-day basis (e.g. transition times). The conduct of the teacher in PE class may help to explain the surprising finding that fitness knowledge is positively related to girls' MVPA. This finding is unexpected because students are often sitting or standing as they listen to the teacher relay information related to the benefits of physical activity. Results indicate, however, that teachers typically provided the fitness knowledge context for less than one minute, suggesting either that minimal time was set aside for it or that fitness knowledge dissemination was done dispersedly throughout the class. It is likely that fitness knowledge was disseminated while the students were engaging in an active task or at the beginning or end of an activity, thereby resulting in a positive association between fitness knowledge and Number of PE minutes spent in MVPA. Teachers might increase the activity of children during inactive contexts (e.g. fitness knowledge) by having students engage in an active task (e.g. warming up) while they instruct or take attendance. Because the relationship between the Number of PE minutes spent in MVPA in boys and fitness knowledge context was not assessed, no conclusions can be made about the relationship between fitness knowledge and boys' MVPA.

Despite the vital role of the teacher in determining PE class structure, the behaviour of the teacher during PE class appears to be less important. None of the teacher behaviour variables showed a significant impact on boys' MVPA, suggesting that boys may be less likely to be influenced by the actions of the teacher during PE class. «Other task» was the sole teacher behaviour that significantly influenced girls' MVPA, showing a positive association. The other task variable involves the teacher performing a behaviour or attending to events that are not related to his or her PE class responsibilities such as turning his or her back on the class, speaking with other school personnel, or leaving the instructional area. Similar to fitness knowledge, teachers spent minimal time engaging in other tasks, however, it appears that they may have done so while the class was being active. Teachers may have directed their attention to an external event while the students were practicing a skill (e.g. dribbling a ball) or playing an active game (e.g. soccer), resulting in a positive association between girls' MVPA and other task.

Data relating to frequency and duration of PE class were also collected. We found that PE classes were offered once a week and lasted on average 33.6 minutes, which indicates that the assessed elementary schools are not meeting the guidelines set by the Mexican Secretary of Public Education, which mandates that PE classes should last at least 
50 minutes and be offered at least twice a week (Administración Federal de Servicios Educativos en el Distrito Federal, 2006). This finding echoes those from a previous study conducted in Mexico City where the average duration of PE class observed in elementary schools was 39.7 minutes (Jennings-Aburto et al., 2009). The limited time allocated to PE class might indicate a prioritising of other school subjects over PE. International reports on physical activity indicate that educators and school staff often do not hold PE classes to the same standard as «academic» subjects, such as math or science, and this could negatively influence the time that is allocated to PE (Marshall \& Hardman, 2000). This was reiterated by Jennings-Aburto and coauthors (2009), who reported that PE classes were often cancelled to accommodate other school activities. It is important to recognize that the part-time school schedule of many public elementary schools in Mexico makes it challenging to allocate time to PE; increasing PE class frequency and duration is typically not feasible. In this context, the role of the PE class teacher becomes especially important. Having an efficient and welltrained teacher leading PE class may help to maximize the amount of MVPA students engage in. Given that our findings corroborate evidence that policy in itself is insufficient to promote significant change (Jenkin, Frommer, \& Rubin, 2006), enhanced accountability for the implementation of policy, which takes into account the unique circumstances and resources of each school, is needed at various levels including classrooms, schools, and school boards.

\section{Limitations}

This study is not free of limitations. First, we studied a circumscribed number of PE class factors that are known to influence MVPA. Other PE class characteristics, such as class size, teacher characteristics (e.g. years of teaching experience), and PE class setting (e.g. square footage of recreation area) were not assessed, which limits our understanding of the factors that influence students' MVPA in PE classes in Mexico. Second, the SOFIT procedure calls for two independent observers to simultaneously code approximately $12 \%$ of all PE lessons. In our study, however, this did not occur and only one observer attended each lesson. Also, it is possible that teachers changed their behaviour in response to being observed. In addition, boys were never exposed to fitness knowledge while being observed and consequently, we could not form any conclusions regarding the relationship between this PE lesson context and boys' MVPA participation. Further, our analysis did not control for correlated errors on children and PE class variables due to school clusters, which may positively bias our findings. Finally, the small, convenience sample of children and low-to-middle income schools included in this study limits the generalizability of our findings to other schools in Mexico. These findings should be interpreted in light of these limitations.

\section{Conclusion}

Game play, skill practice, and fitness lesson contexts had the greatest influence on MVPA in this sample of Mexico City primary school students. Strategies and guidelines aimed at improving MVPA levels during PE class should aim for the effective execution of activities relating to these contexts as well as increased time allocated to these contexts. PE class teachers should also be trained on how to instruct within these contexts effectively in order to use class time efficiently and to balance the contexts such that boys and girls are able to engage in activities that suit their preferences and motivations. Finally, strategies to enhance accountability to policies that encourage physical activity in schools, such as allocating the required frequency and amount of time to PE class, need to be implemented.

\section{Acknowledgement}

This work was conducted with the financial support of a grant (CIHR GIR 112693) from the Canadian Institutes for Health Research (CIHR) Institute of Population and Public Health and the Public Health Agency of Canada -Strategic Initiatives and Innovations Directorate (PHAC-SIID)

\section{References}

Abonce, C. M., Lopez, B. A. M., Gonzalez, M. d. C. R., Ocariz, A. R., \& Benitez, M. A. V. (2010). Acuerdo Nacional para la Salud Alimentaria: Estrategia contra el Sobrepeso y la Obesidad - Programa de Accion en el Contexto Escolar Secretaría De Educación Pública: Secretaria De Educacion Public

Administración Federal de Servicios Educativos en el Distrito Federal. (2006). Dirección General de Educación Física. Dirección General de Planeación, Programación y Evaluación Educativa: Lineamientos para la Organización y Funcionamiento de los Servicios de Educación Física en el Distrito Federa 2006-2007. Mexico City.

Bailey, R. (2006). Physical education and sport in schools: A review of benefits and outcomes. Journal of School Health, 76(8), 397-401.

Cameron, C., Craig, C. L., Wolfe, R., Sport, I., Council, R., \& Fitness, C. (2007). Opportunities for physical activity in Canadian schools: Trends from 2001-2006: Canadian Fitness and Lifestyle Research Institute.

Canadian Society for Exercise Physiology. Canadian Physical Activity Guidelines (all ages) Canadian Sedentary Behaviour Guidelines (0-17 years). from http:// www.csep.ca/english/view.asp?x=890

Cherney, I. D., \& London, K. (2006). Gender-linked differences in the toys, television shows, computer games, and outdoor activities of 5-to 13-year-old children. Sex Roles, 54(9-10), 717-726.

Diario Oficial de la Federación. (2014). Acuerdo Mediante el cual se establecen los lineamientos generales para expendio de bebidas en los establecimientos de consumo escolar de los planteles de educación básica.

Dobbins, M., De Corby, K., Robeson, P., Husson, H., \& Tirilis, D. (2009). School-based physical activity programs for promoting physical activity and fitness in children and adolescents aged 6-18. Cochrane Databases of Systematic Reviews, 1.

Dyson, B. (2014). Quality Physical Education: A Commentary on Effective Physical Education Teaching. Research Quarterly for Exercise and Sport, 85(2), 144-152.

Jauregui, A., Villalpando, S., Rangel-Baltazar, E., Castro-Hernandez, J., Lara-Zamudio, Y., \& Mendez-Gomez-Humaran, I. (2011). The physical activity level of Mexican children decreases upon entry to elementary school. Salud Publica de Mexico, 53(3), 228-236.

Jenkin, R. A., Frommer, M. S., \& Rubin, G. L. (2006). Translating Indicators and Targets into Public Health Action. In D. Pencheon, C. Guest, F. Melzer \& J. A. M. Gray (Eds.), Oxford Handbook of Public Health Practice: Oxford University Press.

Jennings-Aburto, N., Nava, F., Bonvecchio, A., Safdie, M., González-Casanova, I., Gust, T., et al. (2009). Physical activity during the school day in public primary schools in Mexico City. Salud Pública de México, 51(2), 141-147.

Kaminsky, L. A. (2006). ACSM's resource manual for guidelines for exercise testing and prescription. Baltimore, MD: Lippincott Williams \& Wilkins.

Marshall, J., \& Hardman, K. (2000). The state and status of physical education in schools in international context. European Physical Education Review, 6(3), 203-229.

McKenzie, T. L., Feldman, H., Woods, S. E., Romero, K. A., Dahlstrom, V., Stone, E. J., et al. (1995). Children's activity levels and lesson context during third-grade physical education. Research Quarterly for Exercise and Sport, 66(3), 184-193.

McKenzie, T. L., \& Lounsbery, M. A. F. (2013). Physical education teacher effectiveness in a public health context. Research Quarterly for Exercise and Sport, 84(4), 419430.

McKenzie, T. L., Marshall, S. J., Sallis, J. F., \& Conway, T. L. (2000). Student activity levels, lesson context, and teacher behavior during middle school physical education. Research Quarterly for Exercise and Sport, 71(3), 249-259.

McKenzie, T. L., Sallis, J. F., \& Nader, P. R. (1991). SOFIT: System for Observing Fitness Instruction Time. Journal of Teaching in Physical Education, 11, 195-205.

McKenzie, T. L., Sallis, J. F., Prochaska, J. J., Conway, T. L., Marshall, S. J., \& Rosengard, P. (2010). Evaluation of a two-year middle-school physical education intervention: M-SPAN. People, 25

Nader, P. R. (2003). Frequency and intensity of activity of third-grade children in physical education. Archives of Pediatrics \& Adolescent Medicine, 157(2), 185-190.

Pope, R. P., Coleman, K. J., Gonzalez, E. C., Barron, F., \& Heath, E. M. (2002). Validity of a revised system for observing fitness instruction time (SOFIT). Pediatric Exercise Science, 14(2), 135-146.

Rowe, P. J., Schuldheisz, J. M., \& Van der Mars, H. (1997). Validation of SOFIT for measuring physical activity of first-to eighth-grade students. Pediatric Exercise Science, 9, 136-149.

Sallis, J. F., \& McKenzie, T. L. (1991). Physical education's role in public health. Research Quarterly for Exercise and Sport, 62(2), 124-137.

Sallis, J. F., McKenzie, T. L., Alcaraz, J. E., Kolody, B., Faucette, N., \& Hovell, M. F. (1997). The effects of a 2-year physical education program (SPARK) on physical activity and fitness in elementary school students. Sports, Play and Active Recreation for Kids. American Journal of Public Health, 87(8), 1328-1334.

Sallis, J. F., McKenzie, T. L., Beets, M. W., Beighle, A., Erwin, H., \& Lee, S. (2012). Physical education's role in public health: Steps forward and backward over 20 years and HOPE for the future. Research Quarterly for Exercise and Sport, 83(2), 125-135.

Shamah, T., Villalpando, S., \& Rivera, J. (2006). Resultados de nutricion de la ENSANUT 2006. Cuernavaca, Mexico: Instituto Nacional de Salud Publica.

Simons-Morton, B. G, Taylor, W. C., Snider, S. A., \& Huang, I. W. (1993). The physical activity of fifth-grade students during physical education classes. American Journal of Public Health, 83(2), 262-264.

Skala, K. A., Springer, A. E., Sharma, S. V., Hoelscher, D. M., \& Kelder, S. H. (2012). Environmental characteristics and student physical activity in PE Class: Findings from two large urban areas of Texas. Journal of Physical Activity \& Health, 9(4), 481

Te Velde, S. J., De Bourdeaudhuij, I., Thorsdottir, I., Rasmussen, M., Hagströmer, M., Klepp, K.-I., et al. (2007). Patterns in sedentary and exercise behaviors and associations with overweight in 9-14-year-old boys and girls-a cross-sectional study. BMC Public Health, 7(1), 16.

van Mechelen, W., Twisk, J. W. R., Post, G B., Snel, J. A. N., \& Kemper, H. C. G (2000). Physical activity of young people: the Amsterdam Longitudinal Growth and Health Study. Medicine and Science in Sports and Exercise, 32(9), 1610-1616.

WHO. (2010). Global recommendations on physical activity for health. Geneva, Switzerland.: World Health Organization. 